\title{
PODER DIRECTIVO Y NUEVAS TECNOLOGÍAS DE LA INFORMACIÓN Y LA COMUNICACIÓN. UNA ACENTUACIÓN DE LA FACULTAD DE CONTROL*
}

\author{
FABIOLA VERGARA CEBALlos \\ Universidad de Talca
}

\begin{abstract}
RESUMEN: La facultad de dirección del empleador, como manifestación de la propiedad sobre los factores productivos, implica un potencial conflicto con los intereses de los trabajadores, el que cobra nuevas manifestaciones con los avances tecnológicos, que, junto con facilitar las comunicaciones y hacer más eficiente el trabajo al interior de la empresa, aumenta las posibilidades de colisión de derechos fundamentales del trabajador, sobre todo los que guardan relación con el secreto de las comunicaciones y la vida privada e intimidad. En este contexto, cobra relevancia el uso del correo electrónico de propiedad de la empresa. La doctrina y la jurisprudencia han delimitado los límites de vigilancia y control a través de dicho instrumento, en uso del principio de proporcionalidad, a falta de una normativa que responda en forma eficaz a la acentuación del poder de dirección que posibili= tan los cambios tecnológicos.
\end{abstract}

Palabras clave: Facultad de control del empleador, derechos fundamentales de los trabajadores, derecho a la intimidad, secreto de las comunicaciones, correo electrónico.

ABSTRACT: The employer's directional attribution, as a manifestation of the property over the productive factors, implies a potential conflict with the worker's interests, wich gains new manifestations with the tecnological advances; also, to able the communications and make more efficient the work inside the company, intensifies the possibilities of collision of the wroker's fundamental rights, most of all the ones wich are more related with the secret of the communications and the private life and intimacy. In this context, gains relevance the use of the company's electronic mail. The doctrine and the jurisprudence have annotated the limits of vigilance and control trough the mentioned instrument, using the proportional principle, in absence of a normative wich responds in a effective way against the accentuation of the directional power available by the technological changes.

Key words: employer's control attribution, worker's fundamental rights, intimacy right, communication's secret, electronic mail.

* Estudio realizado para la obtención de la suficiencia investigadora en la Universidad de Salamanca, España, 2005.

En la redacción del artículo y de las notas se han utilizado las siguientes abreviaturas:

$A S$

Aranzadi Social (Editorial Aranzadi, Elcano, $\mathrm{Na}$ varra).

AA. $V V$. Autores varios.

$B O E$ Boletín Oficial del Estado (Ministerio de la Presidencia, Madrid).

CC Código Civil.

$C E$ Constitución Española.

$C E D H$ Comisión Europea de Derechos Humanos.

CES Consejo Económico y Social.

$C P R$

$C T$

DT
Constitución Política de la República de Chile.

Código del Trabajo.

Dirección del Trabajo Gobierno de Chile.
ET Estatuto de los Trabajadores.

MTAS Ministerio del Trabajo y Asuntos Sociales.

OIT Organización Internacional del Trabajo.

$O R D$ Ordinario Dirección del Trabajo.

REDT Revista Española de Derecho del Trabajo, Editorial Civitas, Madrid.

$R L$ Relaciones Laborales, Editorial La Ley, Madrid.

STC Sentencia del Tribunal Constitucional.

STS Sentencia del Tribunal Supremo.

STSJ Sentencia del Tribunal Superior de Justicia.

TC Tribunal Constitucional.

TSJ Tribunal Superior de Justicia. 


\section{INTRODUCCIÓN}

La relación laboral tradicionalmente ha comprendido el intercambio de trabajo por salario en el contexto de una organización productiva de la que es titular el empleador/empresario, dotado por ley del poder directivo. En el marco de la libertad de empresa aquel puede organizar los factores productivos tras la consecución de los fines económicos, sociales, benéficos, etc., disponiendo para ello de facultades de distinta índole entre las que destaca el poder de dirección que comprende las potestades de impartir instrucciones, fiscalizar e imponer sanciones disciplinarias. No obstante el reconocimiento constitucional y legal de aquellas, en múltiples ocasiones su ejercicio ha dado lugar a conflictos en el seno de la relación laboral por cuanto los trabajadores sienten que sus derechos fundamentales son conculcados por prácticas que exceden las atribuciones de que son titulares los empleadores. Sin perjuicio de que este conflicto es intrínseco a la relación laboral ${ }^{1}$, no es menos efectivo que aquel ha cobrado fuerza en los últimos decenios atendidas las nuevas manifestaciones del poder de dirección empresarial y específicamente la facultad de control de la prestación gracias a las nuevas tecnologías de la información y la comunicación (NTIC).

En efecto, en la sociedad "de la información” en que la posesión y control de esta es fundamental, el vertiginoso desarrollo de las tecnologías posibilita el acceso a gran cantidad de antecedentes sin las limitantes del tiempo y el espacio. Esta realidad que presenta enormes beneficios para las distintas actividades del diario quehacer conlleva, sin embargo, el peligro de lesionar los derechos fundamentales de las personas. Por cierto, la relación de trabajo no es ajena a esta amenaza; los adelantos no solo han servido para aumentar la productividad en un menor tiempo de trabajo, facilitar las comunicaciones tanto al interior como fuera de la organización productiva y liberar a los empleados de tareas penosas y/o peligrosas, sino que también para incrementar la vigilancia y fiscalización de que son objeto por medio del control y monitoreo en tiempo real ${ }^{2}$, cuestión que puede significar la lesión a sus derechos de dignidad y libertad.

Qué es y cuál es el fundamento del poder de dirección, cómo se ha visto modificado por las modernas tecnologías de la información y la comunicación y en qué forma ello ha supuesto una amenaza a la vigencia de los derechos fundamentales de los trabajadores son las preguntas a las que se intenta dar respuesta en este trabajo. En particular se analiza la fiscalización del correo electrónico, medio de comunicación social suministrado por la informática y la telemática que es utilizado para el desempeño del trabajo convenido.

\footnotetext{
1 En este sentido Palomeque López destaca que "En la relación de intercambio de trabajo por salario, los sujetos que la protagonizan esgrimen o aportan intereses, no solo distintos, sino contrapuestos. Es decir, que en la propia raíz de la relación de trabajo asalariado se halla instalado un conflicto social de carácter estructural: la contraposición de intereses entre quienes dominan los medios de producción y quienes aportan exclusivamente el trabajo dependiente... la plena satisfacción de los unos ha de ser necesariamente en su caso a costa de los propios de la otra parte...". PALOMEQUE LÓPEZ, Manuel Carlos, Derecho del Trabajo e Ideologia, Editorial Tecnos, 2002, p. 21.

2 Es por esto que se habla de la aparición de una sociedad orweliana, en la que derechos básicos de la persona son amenazados.
} 


\section{NOCIONES SOBRE EL PODER DE DIRECCIÓN}

Más allá de la forma de desarrollo de la relación laboral existe una sujeción al poder directivo referido a las características, requisitos y a la propia modalidad de ejecución del trabajo que constituye la potestad para organizar y ordenar el trabajo inicialmente y durante toda la ejecución del contrato ${ }^{3}$, la ordenación última de aquel conforme a los fines productivos del empresario de forma tal que el trabajador debe ajustar su actuar a las disposiciones del empleador para la consecución de la finalidad propia de este y, siguiendo sus directrices, debe coordinar su prestación con la desarrollada por otros trabajadores.

El poder directivo reconocido al empresario por el ordenamiento laboral encuentra su fundamento en el propio contrato de trabajo y es el complemento de un orden económico que tiene como principios los derechos de propiedad y libertad de empresa. El empresario/empleador es el titular de la estructura "empresa" diseñada jerárquicamente para satisfacer sus propios intereses económicos; a ella se integra el trabajador sometiéndose a las diversas facultades de aquel. Es esta la noción del poder de dirección recogida por el ET cuando en su art. 1.1 dispone que el trabajador presta sus servicios "dentro del ámbito de organización y dirección de otra persona". Como reverso de la supremacía empresarial aparece la subordinación del trabajador, esto es, el sometimiento de este al ámbito de organización (cómo ha de prestarse el trabajo) y dirección (de qué manera ha de prestarse el trabajo) del empleador. En el contrato de trabajo la subordinación del trabajador al empresario, entendida en su sentido más genérico, es el elemento principal y necesario para la satisfacción de la finalidad de la relación -la apropiación de los frutosque solo será posible si el segundo logra coordinar y adaptar a sus planes organizativos la prestación contratada de suerte tal que la subordinación modaliza continuamente el desarrollo de la relación de trabajo, de los créditos y obligaciones que asumen las partes ${ }^{4}$.

La jurisprudencia del TSJ, precisando qué debe entenderse por dependencia o subordinación ha señalado que ella existe cuando se dan, entre otras, alguna de las siguientes situaciones:

- El trabajador percibe una retribución fija mensual, además de incentivos, desarrollando su actividad en el local de la empresa, utilizando los medios técnicos de esta, careciendo de organización propia y sujeto a horario, aunque sea exigido con flexibilidad (STSJ de Cataluña, de 8 de abril de 1993);

- Son empleadores quienes, junto con soportar el gasto, asumen funciones rectoras sobre la prestación con facultades de nombramiento y cese de los trabajadores y sobre el tiempo y modo de su trabajo (STSJ de Andalucía-Granada, de 12 de junio de 1992);

- El trabajador hace reparto de mercancías de la empresa dentro de una estricta sujeción a las órdenes y directivas de la propia empresa en cuanto al horario, zonas de distribución y rutas a seguir (STSJ de Cataluña, de 29 de junio de 1993).

\footnotetext{
3 Palomeque lopez, Manuel Carlos; Álvarez de la RoSa, Manuel, Derecho del trabajo, décima edición, Centro de Estudios Ramón Areces, Madrid, 2002, p. 707.

${ }^{4}$ ROMAN DE LA TORRE, M.D., Poder de dirección y contrato de trabajo, Editorial Grapheus, Valladolid, 1992, p. 58.
} 
Ahora bien, esta concepción tradicional de la subordinación personal o jerárquica ha evolucionado a una referida a la prestación de trabajo dentro del ámbito organizativo del empresario ${ }^{5}$. En este cambio han tenido influencia, por cierto, las transformaciones económicas, tecnológicas y organizativas en virtud de las cuales existen trabajadores más cualificados -en ocasiones su nivel de formación puede ser mayor que el de su empleador, lo que dificulta la aceptación pasiva de las órdenes impartidas por este-, ha aumentado el trabajo autónomo -por ejemplo en el sector servicios- y se ha alterado la morfología típica del trabajo subordinado, como en el caso del teletrabajo. Por otra parte y a consecuencia de los procesos de reorganización del trabajo provocados por las innovaciones técnicas, se aprecian dos tendencias a propósito de las repercusiones de aquellas 6 :

- En cuanto a las relaciones de trabajo creadas directamente por la nueva tecnología -la de un técnico en programación, por ejemplo- los vínculos propios de la subordinación aparecen bastante atenuados;

- En lo que respecta a las modificadas por la incorporación de las NTIC, la subordinación sufre una acentuación produciéndose, en beneficio del empresario, un desequilibrio entre las fuerzas que rigen la relación laboral toda vez que la prestación de trabajo se ve sometida a un poder de vigilancia más intenso impreso en el programa informático.

En este punto es necesario tener presente que si bien la subordinación no lesiona la dignidad del trabajador sí pueden hacerlo determinadas formas de control empresarial que, excediendo la estricta evaluación del cumplimiento de la obligación laboral, posibiliten una acentuación desmesurada de aquella. No debe olvidarse que aquel no es infinito sino que está limitado por el concepto de la buena fe y los deberes de diligencia y obediencia, elementos personales que revelando la dependencia modalizan profundamente las relaciones de las partes en el contrato de trabajo, tanto las obligaciones no estrictamente técnicas o funcionales del trabajador como la propia intensidad en que cobran forma y se ejercen los poderes empresariales?

\subsection{CONTENIDO DEL PODER DE DIRECCIÓN}

El poder de dirección comprende la facultad del empresario para impartir instrucciones más o menos generales a sus trabajadores para la ejecución de las prestaciones; además y como apéndices de aquella, el control, la vigilancia de las mismas y el poder disciplinario.

\section{a) Facultad de impartir instrucciones}

El art. 20.2 ET reconoce esta potestad al disponer que el trabajador, en el cumplimiento de su obligación contractual de trabajar deberá atenerse, además de las disposicio-

\footnotetext{
${ }^{5}$ Ibid., pp. 59-61.

6 PEREZ DE lOS COBOS ORIHUel, Francisco, Nuevas Tecnologías y Relación de Trabajo, Editorial Tirant lo Blanch, Valencia, 1990, p. 36, destaca que "Las tecnologías informativas crean, en efecto, una multiplicidad de nuevas figuras laborales de carácter semi autónomo o semi dependientes, no reconducibles al paradigma tradicional del trabajo prestado para otros a tiempo pleno".

7 ROMÁN DE LA TORRE, M.D., op. cit., pp. 62-63.
} 
nes legales y convenios colectivos, a las "órdenes e instrucciones adoptadas por aquél (empresario) en el ejercicio regular de sus facultades de dirección [...]".

Cabe señalar que la doctrina ${ }^{8}$ ha distinguido entre instrucciones y órdenes; las primeras se refieren a la organización genérica del trabajo ${ }^{9}$ (número de trabajadores y organización de los mismos por categorías y funciones; imagen exterior de la empresa, normas sobre calidad y presentación de los bienes y servicios, entre otras), en tanto que las segundas van en relación directa con la dificultad de la labor a realizar, reconociéndose al trabajador el derecho a resistir -ius resistentiae- las que lesionen sus derechos irrenunciables o que impliquen atentados a su dignidad; en general, situaciones que justifiquen la desobediencia. En todo caso, ambas son el instrumento a través del cual el poder directivo del empresario marca no solo la diligencia debida por el trabajador, sino la actividad misma que este debe realizar y la disciplina que debe observar en el lugar de trabajo ${ }^{10}$.

\section{b) Facultad de imponer sanciones - poder disciplinario}

Entendido el poder de dirección como la potestad para organizar y ordenar el trabajo inicialmente y durante toda la ejecución del contrato, parece obvio que aquel comprenda la facultad de imponer sanciones al trabajador en caso de incumplimiento de sus obligaciones laborales. Aun cuando el ordenamiento jurídico reconoce al empresario la potestad disciplinaria "[...] los trabajadores podrán ser sancionados por la dirección de la empresa en virtud de incumplimientos laborales, de acuerdo con la graduación de faltas y sanciories que se establezcan en las disposiciones legales o en el convenio colectivo que sea

\footnotetext{
8 Palomeque López, Manuel Carlos; Álvarez de la RoSa, Manuel, op. cit., p. 708.

${ }^{9}$ El Convenio Colectivo General de Trabajo para la Industria Textil y de la Confección, BOE de 21 de agosto de 2000 , núm. 200, ofrece un ejemplo cuando en su artículo 11 señala que la organización del trabajo comprende:

1. La exigencia de la actividad y, consecuentemente, del rendimiento establecido.

2. La adjudicación del número de máquinas o de la tarea necesaria para la plena actividad del trabajador.

3. La fijación de los índices de desperdicios y de la calidad admisible a lo largo del proceso de fabricación.

4. La vigilancia, atención y limpieza de la maquinaria encomendada, siempre que la misma se haya tenido en cuenta en la determinación de las cantidades de trabajo y actividad.

5. La movilidad y redistribución del personal, con arreglo a las necesidades de la organización y de la producción. En todo caso se respetará la retribución alcanzada y se concederá el necesario período de adaptación.

6. La exigencia de la actividad normal a la totalidad del personal de la empresa.

7. La fijación de la fórmula del cálculo de la retribución de forma clara y sencilla para que los trabajadores puedan fácilmente comprenderla.

8. La aplicación de un sistema de remuneración por incentivo. Si se aplicara solo a una o varias secciones, también lo gozarán aquellas otras que, como consecuencia, experimenten un aumento por encima de la actividad normal de su carga de trabajo por obrero-hora.

9. La realización de las modificaciones en los métodos de trabajo, tarifas, distribución del personal, cambio de funciones y variación técnica de las máquinas y material que faciliten el estudio técnico de que se trate.

10. La adaptación de las cargas de trabajo, rendimientos y tarifas a las nuevas condiciones que resulten del cambio de método operatorio, proceso de fabricación, cambio de materia, máquinas o condiciones técnicas de las mismas.

11. Las cuestiones que se susciten entre empresarios y trabajadores respecto de la organización del trabajo podrán plantearse por la correspondiente representación legal de los trabajadores ante la autoridad o jurisdicción laboral competentes cuando afecten a la calificación profesional, a las retribuciones o a la cantidad o calidad de trabajo razonablemente exigible, que resolverá en los plazos y mediante los trámites que legalmente correspondan.

10 Montoya Melgar, Alfredo, "El poder de dirección del empresario", en: REDT, N 100, año 2000.
} 
aplicable" (art. 58.1 ET), ella no es ilimitada desde el momento que en la legislación ${ }^{11}$ se contienen precisiones relativas a la adopción e imposición de estas sanciones y, por lo demás, la valoración de las faltas y los castigos impuestos son siempre revisables ante la jurisdicción competente.

Ahora bien, el empleador puede determinar de forma individualizada conductas de diferente trascendencia disciplinaria e imponer distintas sanciones - desde una amonestación verbal hasta la extinción del contrato- sin que ello implique la vulneración del principio de igualdad ni un trato discriminatorio respecto de determinados trabajadores ${ }^{12}$ por cuanto para atribuir esta calificación la empresa aprecia indiciariamente, en virtud de su propia depuración de los hechos y como titular del poder disciplinario, que en una concreta situación de incumplimiento de las obligaciones laborales no ha sido idéntica la actitud de los diversos trabajadores infractores ${ }^{13}$.

\footnotetext{
vacaciones u otra minoración de los derechos al descanso del trabajador o multa de haber".

A) Faltas leves:

a) Amonestación verbal.

b) Amonestación por escrito.

c) Un día de suspensión de empleo y sueldo.

B) Faltas graves:

a) Suspensión de empleo y sueldo de dos a sesenta días.

b) Inhabilitación durante dos años o definitivamente para pasar a otra categoría superior.

C) Faltas muy graves:

a) Suspensión de empleo y sueldo de sesenta días a ciento veinte días.

b) Inhabilitación durante dos años o definitivamente para pasar a otra categoría.

c) Despido.
}

${ }^{11}$ En efecto, en el apartado 20 del art. 58 ET se preceptúa, en lo pertinente, que "[...] La sanción de las faltas graves y muy graves requerirá comunicación escrita al trabajador, haciendo constar la fecha y los hechos que la motivan. En el apartado $3^{\circ}$, en tanto, se dispone que No se podrán imponer sanciones que consistan en la reducción de la duración de las

${ }^{12}$ Esta estimación de las faltas también puede hacerse en Convenios Colectivos atendiendo a la importancia, reincidencia e intención de aquellas fijándose, incluso, las consecuencias jurídicas que aquellas traen aparejadas. Es el caso del Convenio Colectivo para el sector de Agencias de Viajes, BOE de 8 de julio de 2003, núm. 162, que en su art. 42 establece que "Las sanciones que las empresas puedan aplicar, según la gravedad y circunstancias de las faltas cometidas, serán las siguientes:

Para la aplicación de las sanciones que anteceden se tendrá en cuenta el mayor o menor grado de responsabilidad del que cometa la falta, categoría profesional del mismo y repercusión del hecho en los demás trabajadores y en la empresa.

En cuanto a prescripción de las faltas, regirán los plazos previstos en el Art. 60.2 del Estatuto de los Trabajadores.

Siempre que se trate de faltas muy graves la empresa podrá acordar la suspensión de empleo y sueldo, como medida previa y cautelar, por el tiempo estrictamente necesario para el esclarecimiento de los hechos, con el límite de un mes, sin perjuicio de la sanción que deba imponerse. Esta suspensión será comunicada a los representantes de los trabajadores. De ser revocada la sanción por la jurisdicción competente, la empresa se verá obligada al abono de los salarios correspondientes a la suspensión cautelar de empleo y sueldo acordada.

Las empresas habrán de comunicar a la representación de los trabajadores y al propio trabajador el pliego de cargo por faltas graves y muy graves en donde se concreten los hechos imputados. Será necesaria la apertura de un período de alegaciones de los representantes de los trabajadores y del propio trabajador con una duración mínima de tres días tras el cual, se hayan presentado o no escritos de alegaciones, la empresa podrá imponer la sanción que considere más adecuada. De la carta de sanción se dará copia a la representación legal de los trabajadores simultáneamente a la comunicación al propio afectado".

Similares disposiciones se contienen en el Convenio Colectivo Estatal de artes gráficas, manipulados de papel, manipulados de cartón, editoriales e industrias auxiliares, BOE de 31 de agosto de 2004, núm. 210, art. 10, apartados 2 y 3 .

13 En este sentido se ha pronunciado la jurisprudencia estableciendo que "en el supuesto litigioso, los compañeros del actor (a quienes se les impuso una sanción inferior a la de despido) también remitieron mensajes por correo electrónico -ajenos a la prestación laboral y durante su jornada de trabajo- a través del ordenador de la empresa y sin consentimiento de esta; aunque, y a diferencia de aquél (además de no constar el contenido de los mismos), este sancionado incumplimiento se manifestó en solo una...o dos ocasiones..., lo que revela la justificación del diferente trato recibido por uno y otros". STSJ de Cataluña, 9382/2000, de 14 de noviembre, FJ $4^{\circ}$ (AS 2000/3444). 
El despido, la más grave y extrema sanción que puede imponerse a un trabajador, requiere de algunas precisiones. En primer lugar, no todo incumplimiento trae aparejado el despido, el que, dada su trascendencia y conforme con la teoría gradualista, debe imponerse solo en último caso tras una adecuada ponderación de la conducta infractora, la persona del trabajador y las circunstancias concurrentes en el caso concreto. Ahora bien, en el art. 54.1 ET se faculta al empresario para unilateralmente poner término al contrato de trabajo por incumplimiento "grave y culpable del trabajador"14, noción que la jurisprudencia ha intentado precisar señalando que la culpabilidad implica un acto u omisión voluntario y consciente, incluso malicioso (STS, de 5 de mayo de 1980) o bien un acto culposo siempre que la culpa sea grave e inexcusable (SSTS 18 de mayo de 1987; 30 de octubre de 1989; 14 de febrero de 1990). En todo caso hay que advertir que no existe unanimidad en la jurisprudencia en torno al requisito de gravedad pues mientras algunos pronunciamientos exigen que aquella deba estar especialmente calificada para merecer el despido, otros estiman que cualquier incumplimiento es merecedor de dicha sanción.

En suma, para la apreciación de los requisitos de gravedad y culpabilidad han de ponderarse todos los aspectos, objetivos y subjetivos, concurrentes en la conducta teniendo presentes los antecedentes, de haberlos, y las circunstancias coetáneas a fin de precisar si en la atribuida al trabajador se dan o no esa gravedad y culpabilidad que, como requisitos de imprescindible concurrencia, exige el artículo 54, apartado $1^{\circ}$ ET (SSTSJ La Rioja, de 26 de mayo de 1998 (AS 1998, 1413); de Andalucía / Málaga, de 26 de enero de 2001 (AS 2001, 1152).

\section{c) Facultad de vigilancia y control de la actividad laboral}

La jurisprudencia ha indicado que la facultad de control se enmarca en el más genérico poder de dirección cuya titularidad y ejercicio atribuyen al empresario diversos artículos del propio ET (STSJ de Murcia, de 6 de febrero de 1998 (AS 1204/1998). Entendida como aquella en virtud de la cual el empleador puede utilizar los medios necesarios para la valoración de la ejecución de la prestación laboral y comprobación de que los trabajadores han cumplido sus obligaciones laborales, comprende una observancia de la conducta de estos en relación con la prestación de servicios en sí misma y sus circunstancias de tiempo y lugar, y con los aspectos laterales o conexos a aquella como, por ejemplo, actividades particulares del trabajador que puedan implicar una competencia desleal para con su empresario. No obstante que la legislación ha reconocido al empresario la potestad para elegir las medidas fiscalizadoras que estime pertinentes para la verificación

\footnotetext{
${ }^{14}$ En el apartado $2^{\circ}$ del referido art. 54 se dispone que se considerarán incumplimientos contractuales:

a) Las faltas repetidas e injustificadas de asistencia o puntualidad al trabajo.

b) La indisciplina o desobediencia en el trabajo.

c) Las ofensas verbales o físicas al empresario o a las personas que trabajan en la empresa o a los familiares que convivan con ellos.

d) La transgresión de la buena fe contractual, así como el abuso de confianza en el desempeño del trabajo.

e) La disminución continuada y voluntaria en el rendimiento de trabajo normal o pactado.

f) La embriaguez habitual o toxicomanía si repercuten negativamente en el trabajo.

g) El acoso por razón de origen racial o étnico, religión o convicciones, discapacidad, edad u orientación sexual y el acoso sexual o por razón de sexo al empresario o a las personas que trabajan en la empresa.
} 
Fabiola Vergara Ceballos / Poder directivo y nuevas tecnologias de la información y la comunicación...

antes referida" 15 "El empresario podrá adoptar las... que estime más oportunas de vigilancia y control [...]" (art. 20.3 ET), la misma se encarga de establecer las limitaciones a que está sujeto en la adopción y aplicación de aquellas: "la consideración debida a su dignidad humana (del trabajador) y [...] la capacidad real de los trabajadores disminuidos, en su caso". Es decir, deben ser oportunas en cuanto a la finalidad concreta de vigilancia y verificadas mediante los procedimientos más adecuados.

\section{LIMITACIONES A LA POTESTAD DE VIGILANCIA Y CONTROL}

Según se ha planteado, el empresario tiene el legítimo derecho de controlar el desempeño de sus trabajadores a fin de obtener los frutos de la organización productiva que ha puesto en funcionamiento y de la que es, en definitiva, responsable. Pero como también se ha precisado en los párrafos precedentes, en la adopción de los sistemas de fiscalización está sujeto a limitaciones. A este respecto la doctrina distingue entre el límite interno objetivo -los contornos de la prestación-y el límite externo -los derechos fundamentales del trabajador-. Mientras que conforme al primero no se puede obtener cualquier información que escape del cumplimiento de la prestación laboral, en virtud del segundo se restringe la aplicación de ciertas formas de control en la relación de trabajo. La legislación, en tanto, se encarga de destacar en los arts. 4, 18 y 20, apartados 2 y 3 ET, que el empresario, en el ejercicio de estas potestades, está limitado por los derechos fundamentales de los trabajadores y el respeto al principio de buena fe (interdicción de la arbitrariedad).

Los derechos fundamentales han sido definidos como aquellos derechos humanos garantizados por el ordenamiento jurídico positivo -en la mayor parte de los casos en su normativa constitucional- y que suelen gozar de una tutela reforzada ${ }^{16}$ proyectados al ámbito de las relaciones entre particulares, estos últimos pueden ser considerados sujetos pasivos o destinatarios de aquellos (Dritwirkung o eficacia horizontal de los derechos). En cuanto valores reconocidos por el constituyente y basados en la dignidad del individuo, aquellos operan como límites al ejercicio de otros derechos y se alzan como barreras infranqueables de los poderes empresariales. Cabe señalar que esta no una afirmación teórica o meramente simbólica, sino que un principio o valor normativo -función unificadora o integradora de los derechos fundamentales- que de forma ineludible debe irradiar y orientar la aplicación e interpretación de las normas laborales debiendo darse primacía de manera indiscutible a aquellos por sobre las potestades fiscalizadoras del empleador ${ }^{17}$. En idéntico sentido se ha pronunciado la jurisprudencia, subrayando la plena vigencia de los derechos fundamentales en el ámbito de la relación de trabajo ${ }^{18}$ de forma tal que si la

\footnotetext{
15 Es la denominada discrecionalidad del poder de control empresarial.

16 PÉREZ LUÑo, Antonio, Los derechos fundamentales, Editorial Tecnos, Madrid, 1984, p. 46.

${ }^{17}$ DT, Dictamen núm. 2856/ 0162 de 30 de agosto de 2002, p. 5.

${ }^{18}$ La STC 99/1994, de 11 de abril, establece en su FJ 4 que “...el contrato de trabajo no puede considerarse como un título legitimador de recortes en el ejercicio de los derechos fundamentales que incumben al trabajador como ciudadano, que no pierde su condición de tal por insertarse en el ámbito de una organización privada...". La STC 90/1997, de 6 de mayo, destaca, por su parte, la plena efectividad de los derechos fundamentales del trabajador en el marco de la relación laboral ya que esta no puede implicar, en modo alguno, la privación de aquellos para quienes prestan servicios en las organizaciones productivas, que no son ajenas a los principios y derechos constitucionales que informan el sistema de relaciones de trabajo.
} 
adopción de determinada medida fiscalizadora es impugnada por los trabajadores por lesionar sus derechos fundamentales - para lo cual bastará con que aporten un indicio razonable de que el acto empresarial los lesiona-, sobre el empleador recae la carga de acreditar que su actuación tiene causas reales, absolutamente extrañas a la pretendida vulneración y que aquellas tuvieron entidad suficiente como para adoptar la decisión respectiva ${ }^{19}$. En todo caso, lo anterior no debe significar desconocer los efectos de la inserción del trabajador en la empresa.

Esta materia, dada su trascendencia, no ha sido ajena a la contratación colectiva, la que, junto con reconocer el poder directivo empresarial, impone restricciones al mismo fundándose principalmente en el respeto a la dignidad humana (art. 10.1 CE). Así, en el convenio colectivo sectorial de Agencias de Viajes (BOE de 8 de julio de 2003) se establece que:

“[...] Los trabajadores tienen como derecho básico, con el contenido y alcance que para cada uno de los mismos disponga su específica normativa, entre otros, al respeto de su intimidad y la consideración debida a su dignidad, comprendida la protección frente a ofensas verbales o físicas de naturaleza sexual. Los actos del empresario que fueren contrarios al respeto de la intimidad y consideración debida a la dignidad de los trabajadores serán constitutivos de infracción laboral (art. 44)”.

En consecuencia, la debida consideración de la dignidad del trabajador supone un límite tácito a la adopción y aplicación de las medidas de vigilancia y control; tácito pero no menos efectivo por cuanto los tribunales se han encargado de confirmar su vigencia y obligatoriedad al interior de la relación de trabajo.

La buena fe, en tanto, desarrollada con carácter general por el Derecho Civil ${ }^{20}$ y acogida por el Derecho del Trabajo como uno de los deberes conexos a la prestación laboral, puede definirse como aquella que busca lograr una convivencia pacífica y próspera entre las personas de una comunidad concretándose en la confianza, en una actuación correcta de otro, en la lealtad de los tratos y en la fidelidad de la palabra dada ${ }^{21}$. No obstante que la normativa legal la entiende como un deber de ambas partes de la relación de trabajo $^{22}$ ha sido concebida como un deber preferente del trabajador ${ }^{23}$, mientras que,

${ }^{19}$ STC 90/1997, de 6 de mayo, FJ 5; STSJ de Cataluña 9382/2000, de 14 de noviembre, FJ 3.

${ }^{20} \mathrm{El}$ artículo 7 CC dispone: "1- Los derechos deberán ejercitarse conforme a las exigencias de la buena fe.

2- La ley no ampara el abuso del derecho o el ejercicio antisocial del mismo. Todo acto u omisión que por la intención de su autor, por su objeto o por las circunstancias en que se realice sobrepase manifiestamente los límites normales del ejercicio de un derecho, con daño para terceros, dará lugar a la correspondiente indemnización y a la adopción de medidas judiciales o administrativas que impidan la persistencia en el abuso".

${ }^{21}$ Garcla Viña, J., La buena fe en el contrato de trabajo. Especial referencia a la figura del trabajador, Consejo Económico Social, Madrid, 2001, p. 22.

$22 \mathrm{El}$ art. 20.3 ET, parte final, dispone que el trabajador y el empresario se someterán, en sus prestaciones recíprocas, a las exigencias de la buena fe.

${ }^{23}$ Demostración de ello es lo dispuesto en distintas normas del ET: "Los trabajadores tienen como deberes básicos: a) Cumplir con las obligaciones concretas de su puesto de trabajo, de conformidad a las reglas de la buena fe y diligencia" (art. 5); "Se considerarán incumplimientos contractuales. d) La transgresión de la buena fe contractual..." (art. 54.2). Las SSTSJ de la Comunidad Valenciana, 2236/1996, de 24 de septiembre, FJ 2; de Cataluña 9382/2000, de 14 de noviembre, FJ 4, y de Cataluña, 5886/2000, de 5 de julio, FJ 4, también insisten en la buena fe como deber exclusivo del trabajador. 
respecto del empresario, se la comprende dentro del genérico de protección que este tiene hacia sus trabajadores, concepción que, en todo caso, parece superada. Es por ello que desde distintos sectores se plantea concebir y en definitiva utilizar la buena fe como un valioso instrumento de control de los poderes unilaterales y discrecionales del empresario -caso típico de la facultad de vigilancia y control del art. 20.3 ET-, a la vez que una restricción de su ejercicio abusivo y/o desproporcionado. Asimismo, la doctrina postula la necesidad de que ella asuma, junto a este carácter negativo/limitativo de los poderes empresariales, un papel positivo en virtud del cual el empleador tenga la obligación de tutela y protección de los derechos fundamentales de sus trabajadores. Ahora, cabe preguntarse cómo operan los derechos fundamentales y la buena fe en la limitación de los poderes directivos empresariales reforzados por las modernas tecnologías de la información y la comunicación.

\section{FACULTAD DE VIGILANCIA Y CONTROL Y NUEVAS TECNOLOGÍAS DE LA INFORMACIÓN Y LA COMUNICACIONN (NTIC)}

\subsection{Generalidades SOBRE LAS NTIC}

La información, definida como la capacidad de acumulación, elaboración y distribución de la experiencia humana por medio de un lenguaje que puede ser oral, mímico o simbólico, es decir, que puede valerse de las facultades humanas del oído, de la vista o de la abstracción ${ }^{24}$, es fundamental en la sociedad actual y prueba de ello es que se la ha denominado "sociedad de la información" o "sociedad informatizada", motivando el surgimiento de un nuevo sector en la economía, el cuaternario o de la información, que está desplazando a los tradicionales primario, secundario y terciario. Es más, se sostiene que la información es poder $y$, por lo tanto, todo quien la posea y/o controle está dotado de una eficaz herramienta. Las NTIC justamente sirven a este objetivo ya que por su intermedio se estructuran y organizan infinidad de datos, facilitando su posterior uso. Entendiendo por NTIC al agrupamiento de descubrimientos científicos, de interrelaciones técnicas y sociales entre grupos homogéneos de innovación y de las múltiples innovaciones subsiguientes que aparecen durante el período de difusión ${ }^{25}$, su incorporación a la vida social y, en particular, a la empresa y a las relaciones laborales han dado origen, como destaca González Ortega, a múltiples exigencias de transformación respecto a las condiciones esenciales de la prestación de trabajo relativas al tiempo, lugar, medio físico y retribución; nuevos requerimientos de los miembros de la organización productiva (formación, aptitudes, conocimientos); cambios en las relaciones internas dentro de la empresa (modo de inserción del trabajo en el sistema productivo global, formas de comunicación, ámbitos de

\footnotetext{
${ }^{24}$ Frosini, Vittorio, Informática y derecho, Editorial Tennis, Bogotá, 1988, p. 29.

${ }^{25} \mathrm{La}$ informática, resultado de la aplicación de las nuevas tecnologías a la información, ha sido definida como la técnica de memorización artificial, de elaboración (es decir, descomposición y recomposición), de transmisión instantánea a distancia, incluso muy considerable, de una serie de informaciones en el lenguaje del calculador electrónico (Deyfrus, Felipe) o como aquella rama de la tecnología moderna que se preocupa del proceso y almacenamiento de informaciones mediante soportes automatizados, es decir, información automatizada o tratada con ayuda de ordenadores electrónicos (Pérez Luño, Antonio).
} 
decisión y autonomía) y nuevas formas de ejercicio de los poderes empresariales. Además, ellas han traído consigo una serie de ventajas por cuanto posibilitan liberar al hombre de labores rutinarias y subalternas para aprovechar al máximo sus facultades creativas facilitando, al mismo tiempo, la apertura de mayores espacios para la seguridad en el trabajo, el ocio y el pleno desarrollo de sus capacidades intelectuales. A lo anterior se ańade que en la sociedad de la información se facilita un diálogo más abierto, una mayor participación, un aumento de las responsabilidades individuales, una mayor resistencia a los poderes fácticos, económicos y sociales; se destaca, en fin, la ampliación de la capacidad de conocimiento, de comunicación y de crítica de los ciudadanos capaces de asumir sus responsabilidades.

Sin embargo, también existen efectos negativos preocupantes que dicen relación con el reforzamiento del autoritarismo tecnocrático en la empresa, lo que contribuye a fomentar la concentración de poder en los managers en detrimento de las fórmulas de participación y cogestión; se intensifican los mecanismos de control laboral ya que "terminales inteligentes" están en condiciones de recoger información relativa al rendimiento de cada trabajador y se experimenta una creciente invasión de la vida privada por las tecnologías de la información y la comunicación ${ }^{26} 27$.

\subsection{NUEVOS MECANISMOS DE VIGILANCIA Y CONTROL DE LA PRESTACIÓN LABORAL}

La potestad en referencia se manifestó tradicionalmente en la imposición de un horario de trabajo fiscalizado mediante una tarjeta o firma de un libro de asistencia; la determinación estricta de las funciones a realizar por los empleados; la existencia de un supervisor directo y "de cuerpo presente" sobre cada trabajador, entre otras. En la actualidad y gracias a la introducción de las NTIC, el empleador cuenta con herramientas más eficaces para fiscalizar el desempeño de los trabajadores ${ }^{28}$ pudiendo, incluso, acceder a los datos privados o vida íntima de estos. Es por esto que se sostiene que los mismos avances tecnológicos que nos presentan a un trabajador más autónomo (la jornada de trabajo es más flexible; la prestación puede realizarse en un lugar distinto del recinto empresarial, etc.) posibilitan un control empresarial más penetrante e intrusivo sobre aquel llegándose a sostener que en nuestros días lo controlado no solo es el trabajo, sino que, además, la persona misma del trabajador ${ }^{29}$. Ahora bien, ¿cómo operan los nuevos mecanismos de

\footnotetext{
26 Otros efectos negativos a tener en cuenta son la disminución de la autonomía personal en el trabajo, acentuándose su componente rutinario; el aislamiento del trabajador debilita los medios de acción colectiva de los movimientos sindicales y genera alteraciones psicosomáticas motivadas por aquel, y surgen nuevos tipos de enfermedades laborales.

27 PEREZ LUÑo, Antonio, Manual de informática y derecho, Ediciones Ariel, Barcelona, 1996, pp. 102 y ss.

28 ZUBAFF, S., "Computer-mediated work: a new world", en: Economic impact, No 41, p. 33, señala que "Como el trabajo ejecutado con uso de videoterminales o de otros mecanismos inteligentes puede ser registrado en todo momento, la presencia del técnico industrial puede incorporarse a todas las actividades en tiempo real por medio de la información inmediata sobre lo que está produciendo cualquier trabajador; mediante listados u otros dispositivos de visualización, los supervisores y directivos pueden aumentar la vigilancia sin depender de controles personales directos. En consecuencia, las relaciones interpersonales pueden perder importancia para la supervisión en lo que se refiere al acceso a la información sobre la cantidad y calidad de la producción del trabajador".

29 Se ha observado que sin desconocer la relevancia de las transformaciones operadas en esta materia las modernas tecnologías no alteran, en esencia, la naturaleza de los poderes empresariales, sino, si acaso, su relevancia relativa y modo de manifestarse.
} 
Fabiola Vergara Ceballos / Poder directivo y nuevas tecnologias de la información y la comunicación...

vigilancia y fiscalización de la prestación laboral? A continuación se revisan solo algunos, basándose en lo apuntado por Mercader Uguina ${ }^{30}$ y en los pronunciamientos judiciales sobre la materia.

a) La Videovigilancia: Está referida a los equipamientos de vigilancia videográfica que mediante instrumentos de pequeñas dimensiones (dos o tres centímetros) que pueden ser ubicados en distintos lugares "estratégicos" y casi sin ser advertidos, permiten obtener cientos de fotografías en cuestión de segundos, permitiendo reconstruir la actividad desplegada por cada trabajador en un momento determinado. Ellos se han instalado en secciones de fabricación continua que durante toda la jornada de trabajo pueden filmar de modo permanente a los trabajadores adscritos a dichas secciones, sus movimientos, desplazamientos, ritmos y actitudes; en empresas de montaje industrial y en hoteles permitiendo obtener la filmación y grabación de imagen y sonido.

b) Vigilancia microfónica: Este mecanismo de control consiste en la instalación, en los lugares de trabajo, de micrófonos destinados a la captación y grabación de sonidos, permitiendo al empresario obtener bastante información sobre las motivaciones e intenciones de sus trabajadores.

c) Etiquetas electrónicas y tarjetas inteligentes: Estos son instrumentos de control integral destinados, en su origen, a los automóviles (el teletrack permite conectar varios vehículos pertenecientes a la misma empresa "siguiéndoles la pista") y que en la actualidad es posible aplicar a seres humanos. Es el caso de los active badges o badges systems que incluyen un microprocesador y transmisores de infrarrojos que posibilitan la identificación del sujeto que los utiliza y permiten, junto a la inicial finalidad de autorizar su acceso a determinadas secciones de la empresa, la gestión de horarios variables y del tiempo de presencia para determinar la duración del trabajo, además del establecimiento de perfiles de comportamientos de los trabajadores.

d) Control computarizado: Gracias a este, una actividad realizada fuera de la empresa, mediante una serie de dispositivos de verificación a distancia, puede ser supervisada como si el trabajador estuviera en los locales de ella. En efecto, existen programas que registran a qué hora el trabajador inicia sus labores, cuándo termina, cuántas llamadas realiza y su duración; se graba su voz y, en general, todo su comportamiento ${ }^{31}$. De esta forma el trabajador que goza de una mayor autonomía e iniciativa en la ejecución de la prestación se puede ver sometido, incluso sin saberlo, a una vigilancia mecánica que lo convierte en simple objeto de medición ${ }^{32}$, cuestión que ha llevado a señalar a la doctrina que la interacción de las operaciones laborales informatizadas rompe la unidad aristotélica del tiempo, lugar y acción sobre la que se había asentado el clásico trabajo industrial e implica una transparencia integral al permitir el control minuto a minuto, como si de una "pecera de peces rojos se tratara"33.

\footnotetext{
30 MerCader Uguina, Jesús, "Derechos fundamentales de los trabajadores y nuevas tecnologías ‘hacia una empresa panóptica?”, en: $R L, \mathrm{~N}^{\circ} 100$, año 2001.

${ }^{31}$ Es el caso típico del teletrabajador cuya actividad puede ser objeto de chequeo periódico y a distancia, supervisándose el número de tecleos por minuto, el número de errores y el tiempo total pasado ante el ordenador.

32 Thibault ARANDA, Javier, El teletrabajo. Análisis jurídico-laboral, Consejo Económico Social, Madrid, 2000, p. 122.

${ }^{33}$ Mercader Uguina, Jesús, op. cit., p. 674.
} 
recibida, archivada o comunicada por medios electrónicos, ópticos o similares como pudieran ser, entre otros, el intercambio electrónico de datos (EDI), el correo electrónico, el telegrama, el télex o el telefax" (art. 2, inciso a). La doctrina, en tanto, ha dicho que es un medio para enviar mensajes escritos de un equipo a otro a través de una red ${ }^{35}$, un equivalente electrónico del correo convencional con papel por el cual las personas pueden enviar mensajes a un receptor o a varios receptores simultáneamente y un medio de transmisión de contenido a distancia por medio de la red de comunicaciones existentes (telefonía fija, inalámbrica o satelital).

Esta difundida herramienta comunicacional suministrada por Internet es un medio electrónico toda vez que utiliza medios electrónicos de gestión y transporte; asíncrono, por cuanto no necesita sincronía de envío y recepción; ubicuo, porque permite su acceso en diferentes lugares; digital, toda vez que utiliza información digitalizada, e informático, porque está en relación con las tecnologías de la información. De estas características se generan una serie de ventajas respecto de otras formas de comunicación tales como el correo postal, teléfono, etc., entre las que se cuentan la rapidez y frabilidad en la recepción y envío de los mensajes, el no requerir simultaneidad del remitente y receptor, la facilidad de archivo, reenvío e integración y su bajo costo. Estas, unidas a las posibilidades de comunicación inmediata "sin fronteras" y su simple utilización son las que han ayudado a extenderlo rápidamente entre la población, incluso entre aquella que no está muy familiarizada con los temas informáticos. Sin embargo, no hay que olvidar que el e-mail también entraña peligros entre los que resaltan la vulnerabilidad de este tipo de comunicación -cualquiera puede conocer, incluso antes que el receptor, el contenido de los mensajes enviados por su intermedio- y la acentuación del control que permite en determinados ámbitos.

\subsection{USO DEL CORREO ELECTRÓNICO EN EL MARCO DE LA RELACIÓN LABORAL}

El correo electrónico que el empleador pone a disposición de los trabajadores para el desarrollo y optimización de aquella ha revolucionado las relaciones laborales porque, atendidas sus características y beneficios, es una herramienta sumamente útil en el desempeño de los servicios. Son estas mismas características las que, empero, facilitan notablemente el control de la actividad encargada y la determinación del rendimiento de los empleados ${ }^{36}$ toda vez que su vulnerabilidad posibilita que el empresario pueda interceptar y conocer el contenido de los mensajes de sus empleados recabando información no solo relativa al trabajo mismo, sino que, además, sobre la vida privada de los empleados (no hay que olvidar que el correo electrónico es percibido no solo como un instrumento de trabajo, sino que también como un medio de comunicación social, al igual que el teléfono o el fax), lo que ha derivado, en ocasiones, en la adopción de sanciones disciplinarias tan graves como el despido. De hecho, se sostiene que si el empresario, en uso de sus potestades fiscalizadoras, intercepta el $e$-mail de los empleados y advierte conductas constitutivas de transgresiones a la buena fe contractual o desobediencia de las órdenes e instrucciones

\footnotetext{
35 Tornabene, María I., Internet para abogados, Editorial Universidad, Buenos Aires, 1999, p. 208.

36 Sanguinetti señala que el correo electrónico es "un codiciado método de control". SANGUINETTI RAYMOND, Wilfredo, Teletrabajo y globalizacion, Ediciones del Ministerio de Trabajo y Asuntos Sociales, Madrid, 2003, p. 11.
} 
respectivas, está legitimado para proceder a la sanción de los infractores, la que podrá consistir en la amonestación por escrito, la suspensión de empleo y sueldo, el traslado del trabajador e, incluso, su despido. Así por ejemplo, el TSJ de Cataluña confirmó la decisión empresarial de extinguir el contrato de un empleado del Deutsche Bank que envió a sus compañeros de trabajo, en un lapso de cinco semanas y durante su jornada laboral, 140 mensajes electrónicos de naturaleza obscena, sexista y humorística, toda vez que dicho trabajador utilizó los medios informáticos de la empresa para fines ajenos a su actividad laboral contraviniendo sus deberes laborales básicos y afectando la productividad del resto de los empleados receptores de sus mensajes (STSJ de Cataluña 9382/2000, de 14 de noviembre (AS 2000/3444).

En algunos casos esta problemática aparece resuelta en reglamentaciones particulares dictadas por las empresas en las que de manera explícita se señala la prohibición del uso de la cuenta de correo electrónico proporcionada por aquella para asuntos personales o distintos del desarrollo de las prestación de trabajo. En el asunto Deutsche Bank, referido en el párrafo anterior, se legitima al empresario para que en su calidad de titular de los medios de producción puestos a disposición de los trabajadores, imponga a estos limitaciones y/o prohibiciones en relación al uso que hagan de aquellos. Es del todo válido, por lo mismo, que el empleador resuelva que el correo electrónico se destinará exclusivamente a fines laborales, prohibiendo su uso para objetos particulares o privados de los trabajadores y que la violación de esta obligación será sancionada. Otra sentencia interesante en esta materia es la del TSJ de Cataluña, 5886/2000 (AS 2000/3452) que confirmó el despido de dos trabajadores por incumplimiento de la reglamentación particular dictada por la empresa sobre la utilización del correo electrónico-Manual Económico Financiero- en la que se advertía a los trabajadores que no estaba autorizado el uso de los medios informáticos de la empresa para asuntos ajenos a la misma. Frente a la fiscalización de sus comunicaciones electrónicas dos trabajadores alegaron la violación de su derecho fundamental al secreto de las comunicaciones, argumento que fue desestimado por el tribunal que estimó que no se estaba en presencia de tal figura, sino que, en realidad, ante una utilización indebida de medios e instrumentos de la empresa; la empleadora estaba facultada para ejercer un control sobre el empleo de los medios de su propiedad, así como sobre la propia actividad laboral del trabajador y, en consecuencia, podía adoptar las medidas que estimara más oportunas de vigilancia para verificar el cumplimiento de las obligaciones y deberes laborales por parte de los trabajadores. El mismo fallo, reflexionando sobre el deber de buena fe, establece que se incurre en una transgresión de aquella y de la confianza que son exigibles en toda relación laboral cuando el trabajador, abusando de esta confianza y utilizando medios que el empresario ha puesto a su disposición para el desarrollo de sus funciones, realiza durante su jornada laboral actividades ajenas a aquellas por las cuales aquel se le retribuye (FJ 4 y 5 ).

Asimismo, algunas organizaciones han implementado la práctica de advertir a sus trabajadores que sus conversaciones telefónicas y mensajes electrónicos podrán ser grabados. Se afirma que si los trabajadores están en conocimiento de este hecho y tienen plena conciencia de que los medios informáticos son de propiedad de la empresa no pueden alegar la vulneración de su derecho al secreto de las comunicaciones toda vez que este no 
e) Automatización de datos: En este supuesto la actividad de control no consiste solo en la obtención o recogida de datos incluso intrascendentes de los trabajadores, sino que requiere, además, el tratamiento de los mismos ${ }^{34}$ con el fin de obtener la información necesaria para satisfacer el fin del control. Gracias a la revolución electrónica esto último es posible toda vez que ella permite reelaborar gran cantidad de antecedentes simples de forma que, combinados entre sí, pueden dar prácticamente el perfil de una persona. Es decir, en la actualidad la máquina ya no se limita a la recepción y transmisión de información, sino que, además, la elabora automáticamente, la "automatiza".

f) Vigilancia telefónica: Este instrumento permite controlar las llamadas efectuadas por los trabajadores que se sirven para su trabajo del teléfono, analizar las conversaciones con los clientes y ver si cumplen con los estándares de la compañía. También es utilizado para efectuar estadísticas sobre la duración, momento y destinatarios de las llamadas realizadas.

Esta sucinta exposición deja en evidencia que los modernos mecanismos de control proporcionados por la informática y la telemática pueden plantear conflictos con el "derecho a la libertad informática" que involucra poder disponer y controlar la información referente a uno mismo $y$, por lo tanto, aceptar o rechazar el uso que otros quieran hacer de ella. En consecuencia, el reforzamiento de esta manifestación del poder directivo empresarial exige redoblar los esfuerzos destinados a asegurar la posición del trabajador ante el ejercicio de aquel y, a este efecto, tanto la legislación como el desarrollo jurisprudencial y doctrinal respectivo postulan circunscribir los mecanismos de fiscalización a la estricta evaluación del cumplimiento de la obligación laboral.

\section{EL CASO DEL CORREO ELECTRÓNICO}

El servicio más tradicional y extendido de Internet -red especialmente abierta- es el correo electrónico (también conocido por su traducción inglesa mail, i-mail o e-mail, que hacen referencia respectivamente al Internet-mail o al electronic-mail). Su nombre viene de la analogía con el correo ordinario por la utilización de "buzones" (servidores) intermedios donde se envían y reciben los mensajes. Creado en 1971 por Ray Tomlinson, este lo desarrolló enviando un mensaje entre dos computadoras que se encontraban en lugares distintos (una al lado de la otra). En ese entonces ya existía un sistema de mensajería en cada computadora que era compartida por varios usuarios, pero no uno que permitiera enviar mensajes a otra computadora de una red. Tomlinson eligió la arroba (@) como divisor entre el usuario y la computadora en la que se aloja la casilla de correo, porque en inglés@se diceat (en). Así, fulano@máquina.com se lee fulano en la máquina.com

De esta herramienta de comunicación se han elaborado una serie de conceptos; la ley Modelo de las Naciones Unidas (CNUDMI) sobre comercio electrónico, de 1966, estableció que por mensaje de datos se "entenderá la información generada, enviada,

\footnotetext{
${ }^{34}$ Esto gracias al computador. En efecto, el computador equivale a una prótesis de la inteligencia humana -software-cuya capacidad de memorizar y combinar datos potencia; hoy él es un "cerebro artificial" en el cual es posible controlar, cotejar y "entrecruzar" entre sí los datos recogidos, agregándolos coherentemente. Frosini, Vittorio, op. cit. p. 23.
} 
se les garantiza y no es exigible; afirmar lo contrario "sería tanto como decir que el empresario no puede ejercer ninguna vigilancia ni control sobre el cumplimiento por el trabajador de sus obligaciones laborales" (STSJ de Cataluña, 5886, del mes de julio de 2000 (AS 2000/3452), FJ 2). La jurisprudencia también ha validado las comunicaciones que las empresas dirigen a sus empleados en las que les informan las condiciones de uso de los medios informáticos puestos a su disposición para el desarrollo de sus prestaciones de trabajo y las restricciones al mismo ${ }^{37}$. El convenio colectivo es otra fórmula para regular el uso de Internet y el correo electrónico en el ámbito laboral, que presenta la ventaja de representar los intereses de trabajadores y empresarios; idealmente, sus estipulaciones responderán a los requerimientos de ambas partes.

Sin embargo, son numerosos los casos en que presentándose este conflicto no hay norma expresa que lo resuelva y entonces son los tribunales de justicia los llamados a zanjar las disputas. Los empleadores sostendrán que el acto de monitoreo e interceptación del e-mail está comprendido en sus facultades directivas y organizativas (art. $38 \mathrm{CE}$ ) y, en consecuencia, la intervención de la o las cuentas de correo electrónico puestas a disposición de sus empleados no es efectuada para conocer aspectos de la vida privada de aquellos, sino que con el objeto de evitar el uso indiscriminado e irresponsable que del mismo se pudiera hacer, derivándose consecuencias económicas y legales que afectan su patrimonio. Entre las primeras se encuentran la pérdida de productividad de los trabajadores que distraen parte de su jornada laboral en asuntos de índole personal, la sustracción de información de propiedad de la empresa, y riesgos como la transmisión de virus informáticos, spams y utilización de programas o software no autorizados; en tanto que las segundas pueden resultar de conductas contrarias a la ley, la moral, el orden público o las buenas costumbres" como la divulgación de información difamatoria, obscena o de contenidos ilícitos, que acarrearán la responsabilidad civil del empresario en su calidad de titular de la empresa y de sus medios informáticos.

Los trabajadores, por su parte, se resisten a que este mecanismo de control sea aplicado libremente y sin cortapisas de ningún tipo toda vez que puede significar la

\footnotetext{
37 Un ejemplo de esta práctica es la comunicación enviada por Telefónica de España a sus trabajadores:

“Aviso: Telefónica de España informa sobre la utilización adecuada del correo electrónico. Últimamente se han venido observando diversos casos de utilizaçión incorrecta del correo electrónico entre empleados de Telefónica de España. Esta nota pretende recordar a los usuarios la política de utilización de esta herramienta, aś como del resto de los recursos, tanto físicos como electrónicos, que la empresa pone a disposición de toda la organización.

No es la primera vez que las Direcciones Generales de Organización y Sistemas de Información y Recursos Humanos advierten sobre la finalidad del correo electrónico. Hace tres años, la Dirección de Relaciones Laborales y Sindicales envió una primera comunicación en este sentido, que fue reiterada posteriormente por otra de fecha 22 de febrero de 2000.

La finalidad del correo electrónico es facilitar la comunicación y colaboración entre los diversos grupos de trabajo. Por tanto, debe ser utilizado para fines exclusivamente laborales en el ámbito de la empresa.

Ni el correo, ni el resto de medios informáticos (Internet, ordenadores, impresoras, etc.) deben ser utilizados para fines privados o particulares. Esto incluye, entre otros, todos aquellos remas relacionados con el ocio, cualquier actividad profesional fuera del ámbito de Telefónica, o la difusión de opiniones personales en remas políticos o de actualidad.

A la vista de los mencionados casos de utilización indebida del correo electrónico, ha de advertirse que la empresa no va a permitir este uso inadecuado y que, por ello, ha abierto el oportuno expediente con el fin de determinar las circunstancias en que se han producido y depurar, en su caso, las responsabilidades que procedan.

Por último, se recuerda que el responsable de cada unidad debe procurar el uso correcto de estos instrumentos o medios de trabajo".
} 
vulneración de sus derechos fundamentales - secreto de las comunicaciones y eventualmente la intimidad-. Existe consenso en torno a que el trabajador no puede desprenderse de su contexto privado durante la jornada de trabajo (CEDH, caso Niemietz c/ Alemania, de 16 de diciembre de 1992) y atendido que el correo electrónico es percibido como un medio de comunicación social, es lógico suponer que a través de este se transmitirá información de diversa naturaleza, a lo que se agrega que los derechos fundamentales no pierden su vigencia con motivo del ingreso al lugar de trabajo; por el contrario, el ámbito de la relación laboral solo modaliza su ejercicio pero en la medida estrictamente imprescindible para el correcto y ordenado desenvolvimiento de la actividad productiva. De ahí que tanto la doctrina como la jurisprudencia indiquen ciertas pautas, condiciones y/o requisitos para la legitimidad de las prácticas empresariales en comento.

Así, las soluciones propuestas por la primera buscan armonizar los intereses en conflicto coincidiendo en la conveniencia de la reglamentación empresarial del uso del correo electrónico que, en todo caso, debe guardar la debida protección y respeto de los derechos fundamentales de los empleados. Pero hay marices. Del Rey Guanter considera que el problema en análisis no se limita al mero uso del e-mail para fines particulares, sino que incluye también la navegación por la red, la descarga irregular de programas informáticos y los problemas de virus, entre otros. Este autor estima adecuado que:

"se establezcan una serie de reglas que pueden emanar, en principio, del poder de decisión de la empresa ya que no es indispensable que ellas sean negociadas o pactada, agregando que si hay un clima adecuado y si las relaciones con la representación de la empresa son las idóneas las reglas tendrían que consensuarse, pero en caso de no existir las condiciones adecuadas la regulación debería hacerse en forma unilateral".

Este ha sido, por lo demás, el criterio asumido por los TSJ.

Marc Basté, por su parte, comentando la sentencia Deutsche Bank (AS 2000/3444) asevera que "aunque el uso profesional del e-mail quede fuera de la concepción común de intimidad, la autonomía organizativa del empresario, donde habría que incluir la revisión de los e-mails, no puede ser ilimitada; es decir otorga importancia a la conciliación de los intereses contrapuestos de las partes". Marc Carrillo, en tanto, se inclina por las soluciones negociadas toda vez que la situación actual obliga, más que a una legislación estatal o supraestatal que lo regule específicamente, al pacto entre las partes en los convenios colectivos que establezcan las condiciones de uso del e-mail. La libertad de empresa, como concepto global y derecho preeminente sobre los demás, no es asumible por el constitucionalismo democrático. Sostiene que el empleador en determinadas circunstancias puede permitir el uso gratuito del e-mail o bien puede acordar que el trabajador lo utilice con fines personales a cambio de que este le pague el costo del servicio. En esta misma línea Falguera i Baró propone que los costos del uso extraproductivo del correo electrónico por parte de los trabajadores puede regularse por el empleador ya que:

"siendo el titular de la empresa el pagador de los gastos inherentes al uso del correo electrónico, no se le puede, de entrada, exigir que vaya a su costa la utilización del mismo para fines personales del asalariado o no relacionado directamente con la 
18.1 de la Carta Fundamental [...] derecho a [...] la intimidad personal y familiar [...], aquella implica la existencia de un ámbito propio y reservado frente a la acción y el conocimiento de los demás necesario, según las pautas de nuestra cultura, para mantener una calidad mínima de la vida humana (SSTC 170/1987, FJ 4; 197/1991, FJ 3; 202/ 1999, FJ 2; 98/2000, FJ 5 y 186/2000, FJ 5).

Las expresiones vida privada e intimidad suelen asimilarse en la literatura y en la legislación; sin embargo, la doctrina precisa que no deben confundirse pues mientras la primera abarca gran parte de las actividades de una persona, la intimidad constituiría el núcleo de la vida privada o su parte más esencial ${ }^{42}$. De esta manera, el concepro de intimidad $[\ldots]$

"se expresa en forma más adecuada y completa en la noción de privacidad, porque esta envuelve el ámbito de una zona de la vida de la persona que debe quedar precisamente excluida de la noticia o de la invasión externa; la intimidad es todavía una zona más profunda y sensible que la privacidad. Es algo todavía más sutil y, por lo tanto, de menor alcance en su extensión".

El término "intimidad" viene del latín intimus que significa lo más recóndito o interior. Ella es concebida, entonces, como "el poder que el hombre tiene de retirarse virtual o provisionalmente del mundo y meterse dentro de sí" o como aquella esfera donde el individuo es capaz de "incubar su acción exterior o desarrollar sus actividades más personales e íntimas". En este mismo sentido los autores norteamericanos Samuel D. Warren y Louis D. Brandeis indican en su artículo "The right to privacy" (1891) que con la expresión intimidad se alude al "derecho a estar solos", to be let alone. Ahora bien, la concepción de este derecho se ha modificado y en nuestros días ya no se la concibe solo en su vertiente negativa, como la facultad de exclusión de los demás, de abstención de injerencias por parte de otro tanto en lo que se refiere a la toma de conocimientos intrusiva como a la divulgación ilegítima de esos datos (STC 186/2000, de 10 de julio, FJ 6), sino que, además, entraña la afirmación positiva del pleno desarrollo de la personalidad del individuo (vertiente positiva), la facultad de ejercer un control sobre las informaciones que le atañen al sujeto; la privacy de la doctrina norteamericana, esto es, el derecho al control de la información referente a uno mismo, a right to control information about oneself. La CEDH, acogiendo esta moderna noción de la intimidad así como también la nueva realidad social tecnológicamente avanzada en la que los derechos fundamentales se ven amenazados, ha señalado que frente al nuevo medio de injerencia en aquella que constituye el poder informático y a manera de solución armonizadora entre poder y libertad, surge la necesidad de asignarle un nuevo contenido al derecho en cuestión que vaya más allá de una mera prohibición de no interferencia ajena y que sea complementado con la posibilidad de que cada ciudadano ejerza un control activo de sus propios datos. Es decir, la propuesta es que aquella sea complementada con una significación positiva de la 42 SERRANO Olivares, Raquel, El derecho a la intimidad como derecho de autonomía personal en la relación laboral, en:
$R E D T, N^{\circ} 103,2001$. 
intimidad, surgida como contrapartida al poder que puede ejercer el Estado u otros particulares mediante la informática.

Lo expuesto en los párrafos precedentes es plenamente aplicable al ámbito de las relaciones laborales, siendo necesario recordar que, tal como ha reiterado la doctrina del TC (por todas, SSTC 57/1994, FJ 6; 143/1994, FJ 6 y 186/2000, FJ 6) el derecho a la intimidad no es absoluto, como no lo es ninguno de los derechos fundamentales, pudiendo ceder ante intereses constitucionalmente relevantes siempre que el recorte que aquel haya de experimentar se revele como necesario para lograr el fin legítimo previsto, proporcionado para alcanzarlo y, en todo caso, respetuoso con el contenido esencial del derecho.

\section{CONCLUSIONES}

Ante la realidad de la incorporación masiva de las NTIC a los distintos ámbitos de la vida cotidiana, incluido el laboral, inevitablemente surgen cuestionamientos en torno a las amenazas y peligros que ellas involucran, sobre todo en lo que dice relación con la vigencia de los derechos fundamentales garantizados a todas las personas. Esto porque no obstante las ventajas que traen aparejadas, las innovaciones tecnológicas acentúan la subordinación del trabajador en la empresa $y$, paralelamente, refuerzan el poder directivo empresarial.

Como en tantas otras ocasiones, la normativa no ha podido responder con la misma celeridad de los acontecimientos para dar respuesta a las problemáticas planteadas por la utilización de las herramientas suministradas por las NTIC en la fiscalización de la prestación de trabajo. Corresponde entonces a la doctrina mediante la reflexión crítica, a la jurisprudencia a través de la interpretación del ordenamiento jurídico respectivo y la conciliación de los intereses contrapuestos y a los particulares, en la celebración de contratos individuales y/o colectivos, lograr la armonización de los derechos de manera que la protección y reconocimiento de unos no suponga el sacrificio absoluto o desnaturalización de otros.

\section{BIBLIOGRAFÍA}

AA. VV., Derecho y Nuevas Tecnologías, Derechos Personalísimos, año 3, Número Especial 4-5, Editorial AD. HOC, Buenos Aires, 2003.

AA. VV., Nuevas tecnologías de la información y la comunicación y Derecho del Trabajo, Editorial Bomarzo, 2004.

CARrILlo, Marc, Privacidad del e-mail, en: http://v2.vlex.com/es/so-emails/entrevista_delrey.asp

DEL REY GUANTER, Salvador, Hay que establecer un equilibrio entre las necesidades de la empresa y los derechos de los trabajadores, en: http://v2.vlex.com/es/sp-emails/entrevista_delrey.asp

FALGUERA I BARÓ, Miguel Ángel, “Uso por el trabajador del correo electrónico de la empresa para fines extraproductivos y competencias de control del empleador", en: Relaciones Laborales, $\mathrm{N}^{\circ} 22$, Editorial La Ley, Madrid, año 2000.

FrosinI, Vittorio, Informática y derecho, Editorial Tennis, Bogotá, 1988.

GARCIA VIÑA, J., La buena fe en el contrato de trabajo. Especial referencia a la figura del trabajador, Consejo Económico Social, Madrid, 2001. 
Fabiola Vergara Ceballos / Poder directivo y nuevas tecnologias de la información y la comunicacion...

MERCADER Uguina, Jesús, "Derechos Fundamentales de los trabajadores y nuevas tecnologías: ¿hacia una empresa panóptica?", en: Relaciones Laborales, N 10, Editorial La Ley, Madrid, año 2001.

MONTOYa Melgar, Alfredo, "El poder de dirección del empresario", en: Revista Española de Derecho del Trabajo, Editorial Civitas, Madrid, $N^{\circ} 100$, año 2000.

Palomeque LOPEZ, Manuel Carlos, Derecho del Trabajo e Ideologia, Editorial Tecnos, Madrid, 2002.

Palomeque López, Manuel Carlos y Álvarez De la Rosa, Manuel, Derecho del Trabajo, décima edición, Editorial Centro de Estudios Ramón Areces, Madrid, España, 2002.

PÉREZ LuÑo, Antonio, Manual de Informática y Derecho, Ediciones Ariel, Barcelona, 1996.

PÉrez LuÑo, Antonio, Los Derechos Fundamentales, Editorial Tecnos, Madrid, 1984.

Pérez DE los Cobos ORihuel, Francisco, Nuevas Tecnologías y Relación de Trabajo, Editorial lo Blanch, Valencia, 1990.

Rodriguez RuIZ, Blanca, El Secreto de las Comunicaciones: tecnología e intimidad, Ediciones McGraw-Hill, Madrid, 1998.

Román de la TOrre, M.D., Poder de dirección y contrato de trabajo, Editorial Grapheus, Valladolid, 1992.

Ruiz Castillo, M. M., "Delimitación subjetiva del Derecho del trabajo", en: Relaciones Laborales, $\mathrm{N}^{\circ} 15-$ 16, Editorial La Ley, Madrid, 1991.

SANGUINETTI RAYMOND, Wilfredo, Teletrabajo y Globalización, Ediciones Ministerio de Trabajo y Asuntos Sociales, Madrid, 2003.

SERRANO OlIVARES, Raquel, "El derecho a la intimidad como derecho de autonomía personal en la relación laboral”, en: Revista Española de Derecho del Trabajo, Editorial Civitas, No 103, Madrid, año 2001.

Thibault Aranda, Javier, El teletrabajo. Análisis jurídico-laboral, Consejo Económico Social, Madrid, 2000.

TORNABENE, María I., Internet para abogados, Editorial Universidad, Buenos Aires, 1999.

ZUBAFF, S., "Computer-mediated work: a new world", en: Economic impact, No 41. 